\title{
Review Article: Numerical analysis of the seismic behaviour of earth dam
}

\author{
Y. Parish, M. Sadek, and I. Shahrour \\ Laboratory of Mechanics of Lille, University of Science and Technology of Lille, 59650 Villeneuve d'Ascq, France
}

Received: 24 July 2008 - Revised: 5 February 2009 - Accepted: 16 March 2009 - Published: 23 March 2009

\begin{abstract}
The present study concerns analysis of the seismic response of earth dams. The behaviour of both the shell and core of the dam is described using the simple and popular non associated Mohr-Coulomb criterion. The use of this constitutive model is justified by the difficulty to obtain constitutive parameters for more advanced constitutive relations including isotropic and kinematic hardening. Analyses with real earthquake records show that the seismic loading induces plasticity in a large part of the shell and in the lower part of the core. Analysis shows that plasticity should be considered in the analysis of the seismic response of the dam, because it leads to a decrease in the natural frequencies of the dam together to energy dissipation, which could significantly affect the seismic response of the dam. Plastic analysis constitutes also a good tool for the verification of the stability of the dam under seismic loading.
\end{abstract}

\section{Introduction}

Seed et al. $(1978,1979)$ reported that the seismic performance of embankment dams has been good in general, except when liquefaction or unusual circumstances have been involved. They noted that a well-built compacted embankment dam can withstand moderate earthquake shaking, with peak accelerations of $0.2 \mathrm{~g}$ and more, with no detrimental effects. The efficiency of modern compacted embankment dams was further demonstrated in 1994 when the Los Angeles Reservoir was severely shaken by the Northridge Earthquake (Davis and Sakado, 1994). The seismic performance of embankment dams has been closely related to the nature and state of compaction of the fill material USCOLD (1992,

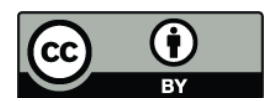

Correspondence to: M. Sadek (marwan.sadek@polytech-lille.fr)
2000). Well-compacted modern dams can withstand substantial earthquake shaking with no detrimental effects.

The pseudo static approach is largely used in engineering practice to assess the seismic stability of earth fill dams. In this approach, the earthquake effect on a potential soil mass is represented by means of equivalent static horizontal force equal to the soil mass multiplied by a seismic coefficient. This approach is quite simplistic since it attempts to represent complex dynamic behaviour in terms of static forces. Stability is expressed in terms of an overall factor of safety. The implicit assumption is that the soil is rigid-perfectly plastic behaving as an undeformable block.

Since the 1971 San Fernando earthquake in California (Ming and Li, 2003), major progress has been achieved in the understanding of the earthquake action on dams. Gazetas (1987) discussed the historical developments of theoretical methods for estimating the dynamic response of earth dams to earthquakes ground excitation. He outlined their important features, their advantages and limitations. Progress in the area of geotechnical computation and numerical modeling offers interesting facilities for the analysis of the dam response in considering complex issues such as the soil non linearity, the evolution of the pore pressure during the dam construction procedure and real earthquake records. Detailed analysis techniques include equivalent linear (decoupled) solutions, and non linear finite element and finite difference coupled or decoupled formulations (Lin and Chao, 1990; Abouseeda and Dakoulas, 1998; Cascone and Rampello, 2003).

Wood (1973) showed that where the frequency at which the principal energy of the input motions approaches the fundamental frequency of the unrestrained backfill, dynamic amplification becomes an important factor, which is not considered in engineering approaches that assess the earth fill dam stability. The paper presents a numerical study of the seismic behaviour of earthfill dams. It will mainly focus on

Published by Copernicus Publications on behalf of the European Geosciences Union. 


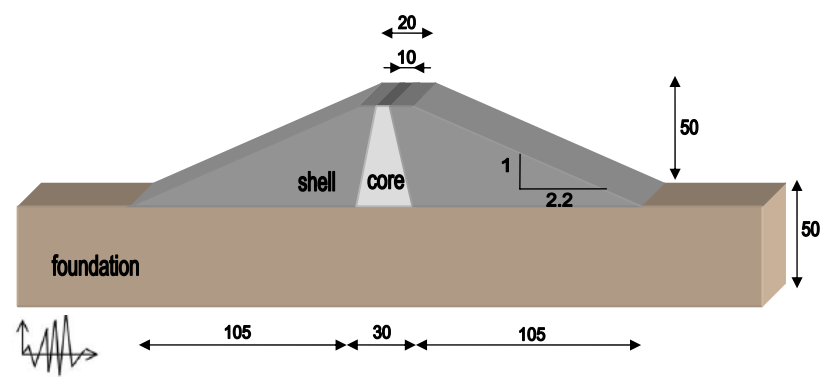

Fig. 1. Geometry of dam and the shape of zones (units in meter).

seismic amplification at the dam crest under real earthquake records with frequency content close to the natural frequency of the dam. In the present study, analysis is conducted using a 3-D finite difference modeling. It corresponds to the response of the dam before water impoundment. Results are presented first considering linear visco-elastic behaviour for the dam material; then analyses are conducted within the framework of plasticity in order on investigate the influence of plasticity on the seismic response of the dam. Indeed, plasticity could affect both the material damping and the dominant frequencies of the dam.

The elastoplastic analysis constitutes an efficient tool for the investigation of the stability of dams under seismic loading. The seismic induced displacement could be used for the evaluation of the stability of the dam. Since the displacement is dependant on the geometric and mechanical properties of the dams as well as the frequency and amplitude of the input loading, a specific study could be conducted for the analysis of the influence of the major input parameters on the stability of the dam. This analysis is not presented in this paper.

This paper does not consider the fluid-skeleton interaction, which could have a significant influence on the seismic response of the dam. This issue was recently investigated by the authors (Parish et al., 2008).

\section{Problem under consideration}

The selected example is a simplified representation of typical earth dam geometry. The dam section assumed in the present survey is a symmetric zone section with clay core and foundation as shown in Fig. 1. Geotechnical properties used in the analyses are presented in Table 1 for foundation soil and earth dam materials. The materials properties are chosen more close to reality. The foundation is assumed to be stiff with a Young's Modulus $E=1000 \mathrm{MPa}$. The Young's modulus of the shell is equal to $60 \mathrm{MPa}$, while that of the core is equal to $40 \mathrm{MPa}$

\subsection{Numerical model}

Numerical analyses are conducted using the finite difference program FLAC3D based on a continuum finite difference
Table 1. Properties of foundation and earth dam soils.

\begin{tabular}{lllll}
\hline & Units & Foundation & $\begin{array}{l}\text { Earth dam } \\
\text { Core }\end{array}$ & Shell \\
\hline Dry density $(\rho)$ & $\left(\mathrm{kg} / \mathrm{m}^{3}\right)$ & 2200 & 1800 & 2000 \\
Young's modulus $(\mathrm{E})$ & $(\mathrm{MPa})$ & 1000 & 40 & 60 \\
Poisson's ratio $(\nu)$ & & 0.25 & 0.30 & 0.30 \\
Elastic shear modulus $(\mathrm{G})$ & $(\mathrm{MPa})$ & 400 & 15.38 & 23.08 \\
Bulk modulus $(\mathrm{K})$ & $(\mathrm{MPa})$ & 666.67 & 33.33 & 50.00 \\
Cohesion $(\mathrm{C})$ & $(\mathrm{kPa})$ & - & 100 & 0.10 \\
Plasticity Friction angle $(\phi)$ & $($ Degree $)$ & - & 15 & 35 \\
Dilation angle $(\psi)$ & $($ Degree $)$ & - & 3 & 10 \\
\hline
\end{tabular}

discretization using the Langrangian approach (FLAC3D, 2005).

This program is based on a continuum finite difference discretization using the Langrangian approach. Every derivative in the set of governing equations is replaced directly by an algebraic expression written in terms of the field variables (e.g. stress or displacement) at discrete point in space. For dynamic analysis, it uses an explicit finite difference scheme to solve the full equation of motion using lumped grid point masses derived from the real density surrounding zone. The calculation sequence first invokes the equations of motion to derive new velocities and displacements from stresses and forces. Then, strain rates are derived from velocities, and new stresses from strain rates. Every cycle around the loop correspond to one time step. Each box updates all of its grid variables from known values that remain fixed over the time step being executed.

Dynamic loading is applied at the base of the foundation layer as a velocity excitation. Kuhlemeyer and Lysmer (1973) showed that for an accurate representation of the wave transmission through the soil model, the spatial element size, $\Delta l$, must be smaller than approximately one-tenth to one-eighth of the wavelength associated with the highest frequency component of the input wave i.e.,

$\Delta l \leq \lambda / 10$

$\lambda$ is the wave length associated with the highest frequency component that contains appreciable energy. The consequence is that reasonable analyses may be time and memory consuming. In such cases, it may be possible to adjust the input by recognizing that most of the power for the input history is contained in lower frequency components.

The procedure of Free-Field Boundaries used in FLAC3D aims absorbing outward waves originating from the structure. The method involves the execution of free-field calculations in parallel with the main-grid analysis. The lateral boundaries of the main grid are coupled to the free-field grid by viscous dashpots to simulate a quiet boundary.

Rayleigh damping $R_{d}=5 \%$ is used in the analyses to compensate for the energy dissipation through the medium (Paolucci, 2002; Lokmer et al., 2002). The behaviour of the 

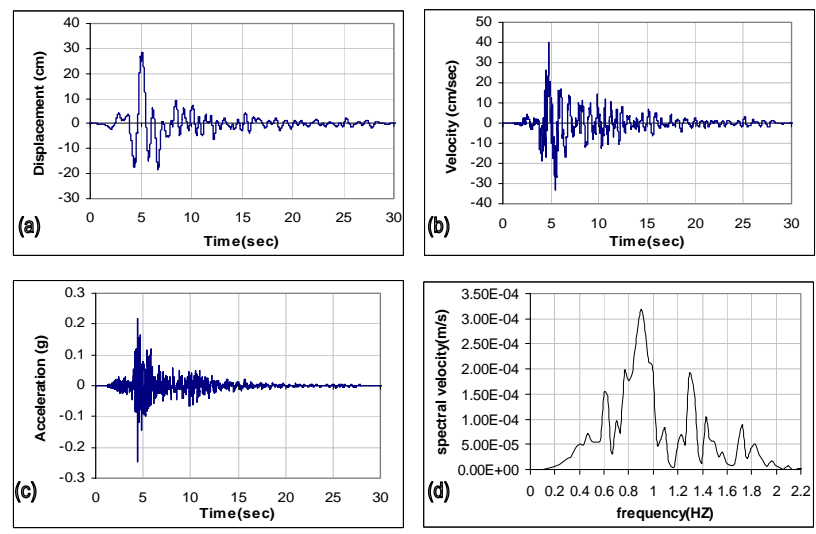

Fig. 2. Kocaeli earthquake record, 1999 (Ambarli Station, Record ID P1086) (a) Displacement,(b) Velocity, (c) Acceleration, (d) Fourier Spectra of Velocity Component.

shell and core of the dam is described using the non associated Mohr Coulomb criterion (Table 1); in this case the hysteretic damping is considered using Rayleigh damping $R_{d}=2 \%$. The use of this model is justified by the difficulty to obtain constitutive parameters for more advanced constitutive relations including both isotropic and kinematic hardening.

\subsection{Input loading}

Dynamic loading is applied at the base of the foundation layer as a velocity excitation. The earth dam is subjected to earthquake loading representative of the 1999 Kocaeli earthquake in Turkey ( $M w=7.4$, Chen and Scawthorn 2003). The estimated peak velocity is approximately $40 \mathrm{~cm} / \mathrm{s}$ (peak acceleration $0.247 \mathrm{~g}$ ), and the duration is approximately $30 \mathrm{~s}$. The record for base acceleration, velocity, and displacement waves are shown in Fig. 2a, b and c (records at Ambarli Station). Fourier analysis of the earthquake velocity record results in a power spectrum depicted in Fig. 2d. The velocity spectrum reveals a dominant frequency of about $0.9 \mathrm{~Hz}$ (the second peak is observed at $1.3 \mathrm{~Hz}$ ). Also note that most of the power for the input history is contained in low frequencies. From the other hand, the natural frequencies of the foundation-dam system were determined by a Fourier analysis of the free vibration response of the dam (Fig. 3). It shows a fundamental frequency $f_{1}=0.7 \mathrm{~Hz}$ which is close to dominant frequency of seismic loading $(f=0.9 \mathrm{~Hz})$; the second frequency is close to $f_{2}=1.4 \mathrm{~Hz}$ (close to the second peak $1.3 \mathrm{~Hz}$ )

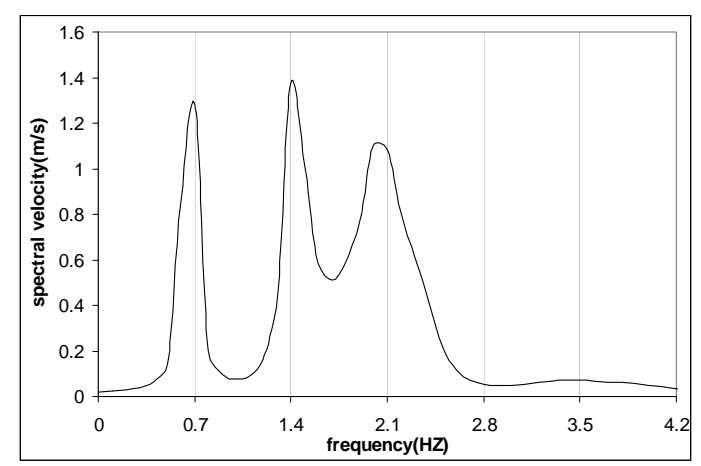

Fig. 3. Response spectra of free horizontal motion at the dam crest.

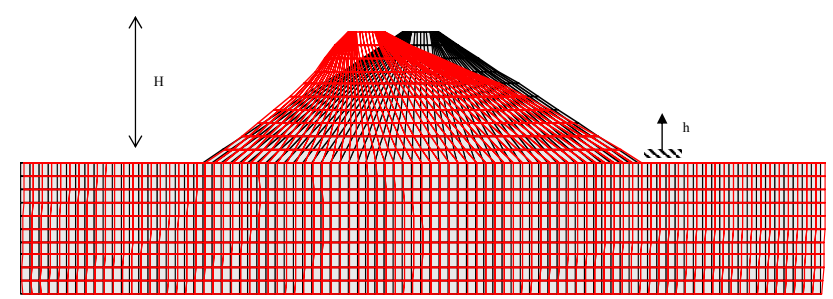

Fig. 4. Dam deformation at the maximum of excitation (Kocaeli earthquake record) $\left(U_{\max }=0.30 \mathrm{~m}\right.$ at the dam crest $)$.

\section{Analysis of the seismically induced response in the dam}

\subsection{Elastic response}

The response of the dam at the maximum excitation is presented in Fig. 4. It shows an increase in the horizontal amplification at the upper part of the dam. Figure 5 shows the velocity amplification in the axis of the dam. It can be observed that the amplification increases with the distance from the foundation; it attains 3.45 at the top of the dam. Figure 6 shows the variation of the lateral amplification in the horizontal direction at the middle height of the dam and the crest. In the first section, we observe a variation in the dynamic amplification between 2 and 2.5. At the crest, we observe a uniform distribution of the amplification (close to 3.45 ).

\subsection{Influence of Plasticity}

Figure 7 shows the location of the zones concerned by plastic deformation at the peak of the seismic excitation. It can be observed that plasticity is induced in a large part of the shell and in the lower part of the core. The upper part of the core remains in the elastic domain. Figure 8 shows the displacement pattern in the axis and the middle height of the dam at the maximum of seismic excitation. It can be observed that the displacement in the axis of the dam is close to the first mode of the dam; the variation of the displacement at the middle height shows a sharp increase at the extremities, 

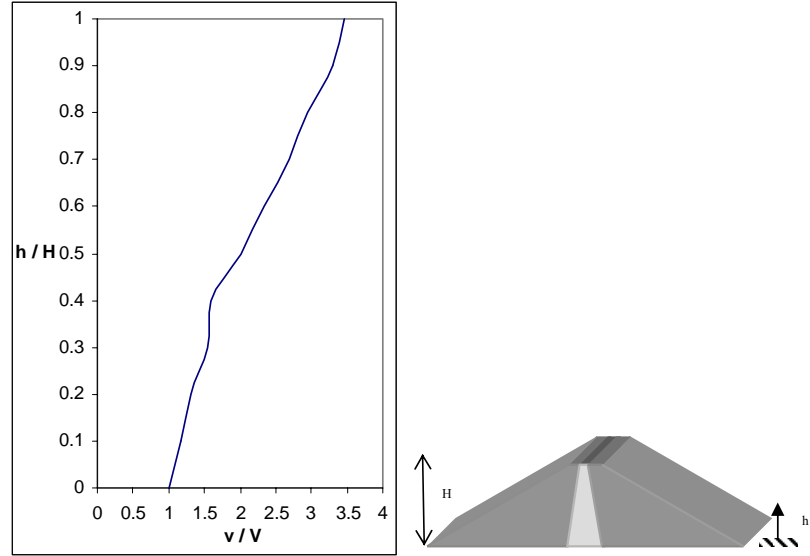

Fig. 5. Velocity amplification in the dam axis (Kocaeli earthquake record) ( $V$ : velocity at the base for $h=0)$.

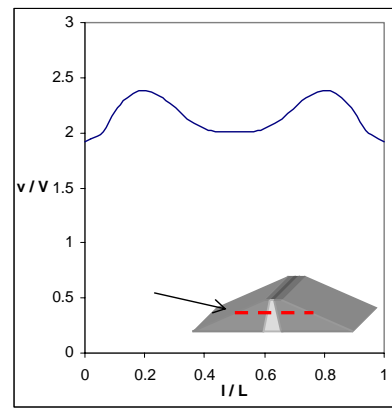

(Middle height)

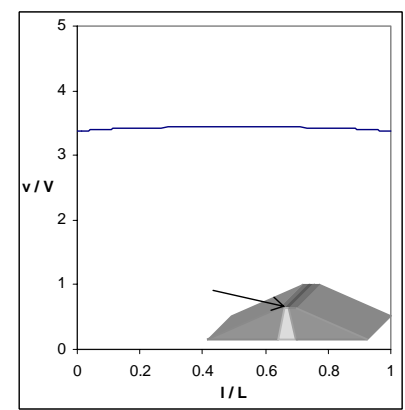

(Dam crest)
Fig. 6. Variation of the amplification in the horizontal direction.

which could indicate the imminence of soil instability in this area. The residual (permanent) displacement is presented in the Fig. 9 that shows the seismic induced residual displacement in the upper part of the dam and the extremities. As seen from this figure, whereas the residual displacement almost unvarying in the lower two-thirds of the crest, it displays significant increase in the upper one-third of the dam. In fact, previous research works indicated this behaviour (Ohmachi and Kuwano, 1994; Ozkan et al., 2006). That's why in the design of embankment dams, due to the stronger shaking at the upper parts, special attention should be given to the crest to avoid undesirable deformations.

Figure 10 shows a comparison between the elastic and elastoplastic analyses at the maximum of velocity. It can be observed that the plastic deformation leads to a decrease in the velocity amplification, in particular in the upper part. This reduction attains about $50 \%$. This result could be attributed to the energy dissipation by plastic deformation and to the influence of plasticity on the reduction of the fundamental frequencies of the dam as illustrated Fig. 11, which shows the influence of plasticity on the spectral response at the crest of the dam.

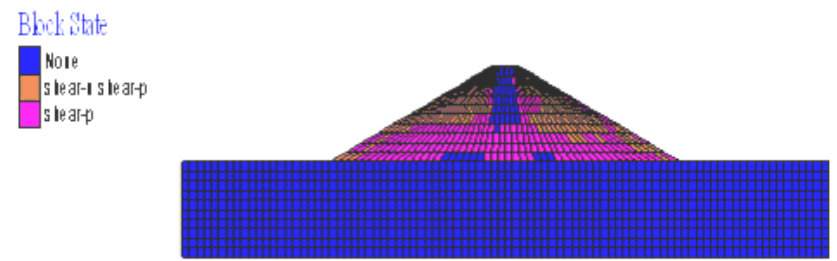

Fig. 7. Reference example: Distribution of plasticity in the dam (at maximum excitation).

(-n: the zone is at active failure now; -p: the zone has failed in the past; shear: yield criterion -shear failure).

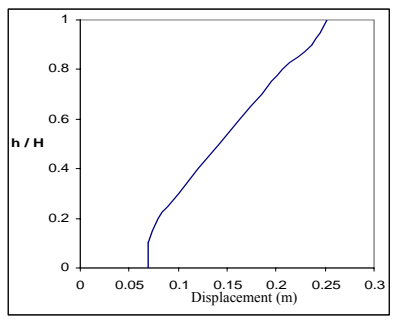

(Vertical axis of the dam)

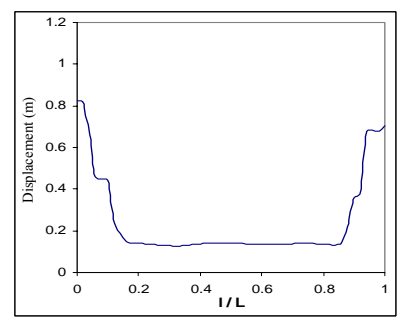

(Middle height of the dam)
Fig. 8. Displacement pattern at maximum of velocity.

\subsection{Influence of the input loading}

This section presents an analysis of the influence of both the frequency content and the loading amplitude on the seismic response of the dam.

\subsubsection{Frequency content of seismic excitation}

The seismic performance of the dam is analysed through time-history analysis using the 1978 Tabas earthquake record that has been adjusted to have a maximum amplitude velocity of $0.4 \mathrm{~m} / \mathrm{s}$ in order to compare it with the response under Kocaeli earthquake. The time history of this record is illustrated in Fig. 12 (9101 Tabas Station). Note that the dominant frequency of this record is about $0.5 \mathrm{~Hz}$.

Figure 13 shows a comparison between the dynamic amplification profiles obtained with the elastoplastic analyses of the dam subjected the Kocaeli and Tabas earthquake records. We observe an agreement between these profiles. The maximum velocity due to the Tabas earthquake record is equal to $1.26 \mathrm{~m} / \mathrm{s}(v / V=2.97)$; this value is higher than that obtained with the Kocaeli earthquake record $\left(V_{\max }=0.95 \mathrm{~m} / \mathrm{s}\right.$, $v / V=2.59)$.

Figure 14a and $\mathrm{b}$ depict the response spectra obtained with the Kocaeli and Tabas earthquake records together with the input motions respectively for elastic and elastoplastic modeling. For elastic analysis, it can be observed that maximum peak of the response to Tabas earthquake (respectively Kocaeli) occurs at the first frequency of the dam $f_{1 \mathrm{dam}}=0.7 \mathrm{~Hz}$ (respectively at $f_{2 \mathrm{dam}}=1.4 \mathrm{~Hz}$ ) while the second peak is 


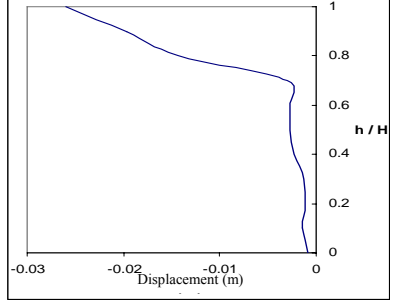

(Vertical axis of the dam)

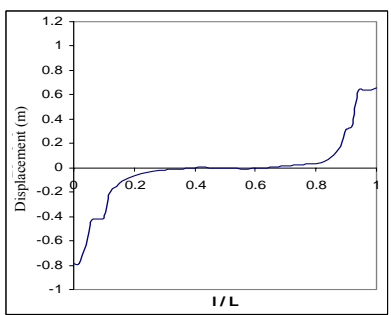

(Middle height of the dam)
Fig. 9. Residual displacement.

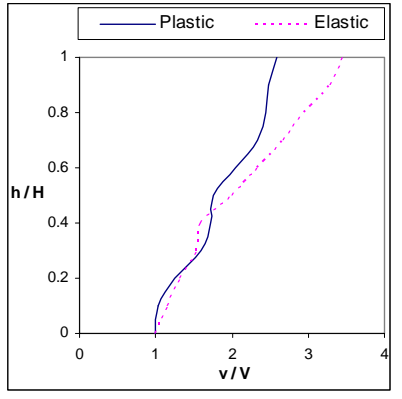

(Vertical axis of the dam)

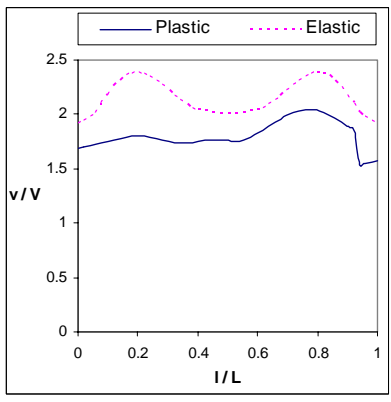

(Middle height of the dam)
Fig. 10. Reference example: Influence of plasticity on the maximum of velocity.

obtained at the first loading frequency $f_{1 \text { load }}=0.50 \mathrm{~Hz}$ (respectively at $f_{2 \text { load }}=1.3 \mathrm{~Hz}$ ). When plasticity is considered, the maximum spectral velocity are obtained at the loading dominant frequencies $\left(f_{1 \text { load }}=0.50 \mathrm{~Hz}\right.$ for Tabas; and $f_{2 \text { load }}$ for Kocaeli).

\subsubsection{Loading amplitude}

The influence of the loading amplitude on the dam response to the Kocaeli earthquake record was investigated through analyses conducted for three values of amplitude of the input motion $\left(V_{a}=0.40,1.60\right.$ and $\left.3.60 \mathrm{~m} / \mathrm{s}\right)$. Such values are extremely high, they are considered for parametric studies. Figure 15 shows the influence of the input motion amplitude on the distribution of plasticity in the dam. The plasticity distribution increases with the loading amplitude. For both $V_{a}=1.60$ and $3.60 \mathrm{~m} / \mathrm{s}$, plasticity extends to the totality of the dam. Note that these values of ground velocity correspond to extremely high-magnitude earthquakes.

Figure 16 shows the influence of the loading amplitude on the maximum of displacement in the vertical axis and at the middle height of the dam. It can be observed that the increase in the input motion amplitude leads to an important increase in this displacement, in particular near the lateral extremities of the dam, where the displacement attains $3.5 \mathrm{~m}$ for $V_{a}=3.6 \mathrm{~m} / \mathrm{s}$ which indicates collapse. The variation of the

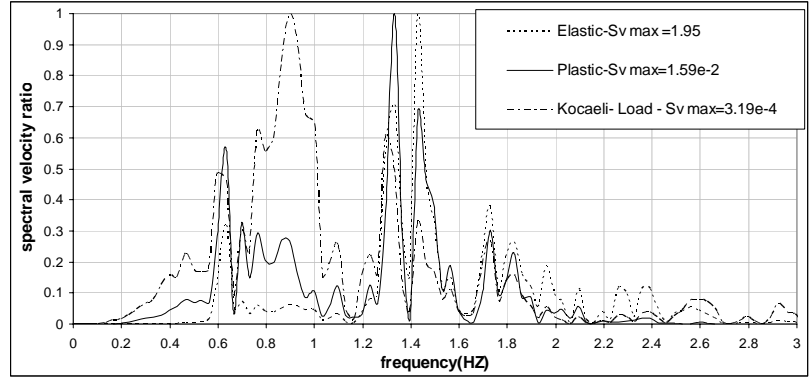

Fig. 11. Reference example: Influence of plasticity on velocity spectra at the dam crest.
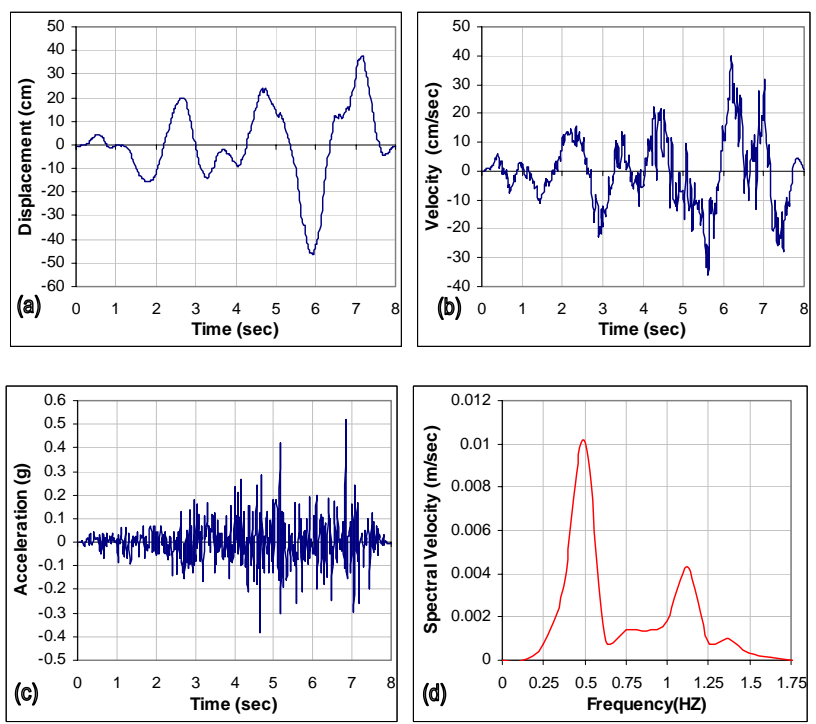

Fig. 12. Tabas earthquake record (9101 Tabas Station) (a) Displacement, (b) Velocity, (c) Acceleration, (d) Spectra.

displacement in the horizontal direction clearly indicates the presence of instability at high amplitude of the input motion.

\subsection{Mechanical role of Core and Shell}

In order to investigate the mechanical role of the core relative to the shell on the overall seismic induced response of the dam. Numerical simulations are carried out with the Kocaeli earthquake record. Analyses were conducted with different values of the core cohesion $\left(100 \times 10^{5} \mathrm{kPa}\right)$ and the shell cohesion $\left(0.1 \mathrm{kPa} \times 10^{5} \mathrm{kPa}\right)$ as described in Table 2 . High values of the cohesion in are used to elucidate the influence of plasticity on the response of the dam.

Figure 17 presents a comparison results for different models in term of the velocity amplification in three sections of the dam: vertical axis, middle height and the crest. It can be seen that the variation of core cohesion doesn't induce a significant change in the seismic amplification. Consideration of plasticity in the shell (cohesion $=0.1 \mathrm{kPa}$ ) leads to a 


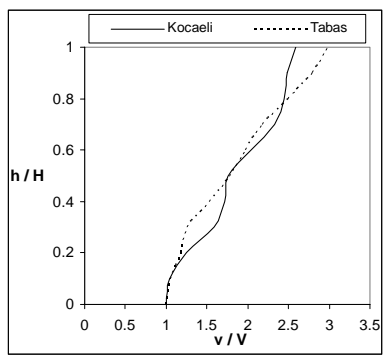

(Vertical axis of the dam)

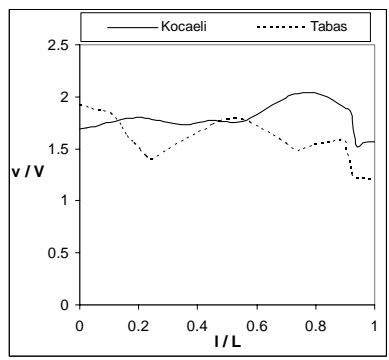

(Middle height of the dam)
Fig. 13. Comparison of the elastoplastic responses to the Kocaeli and Tabas earthquake records.

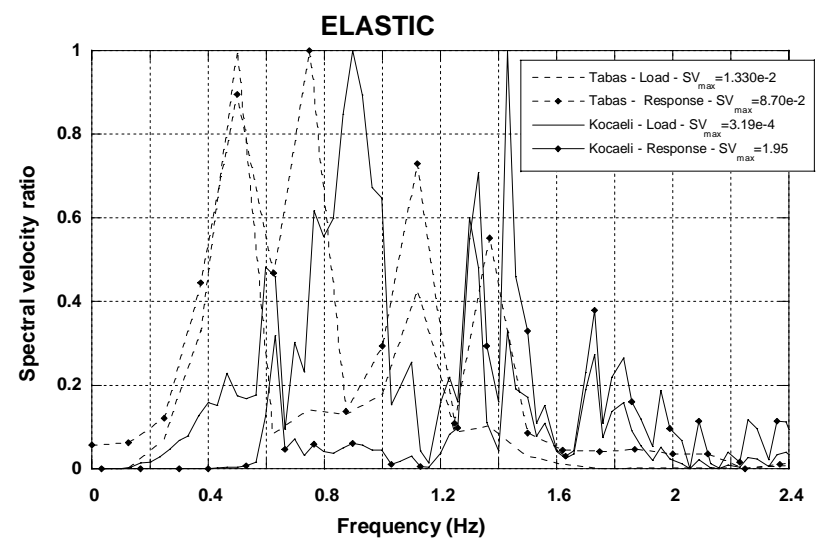

(a)

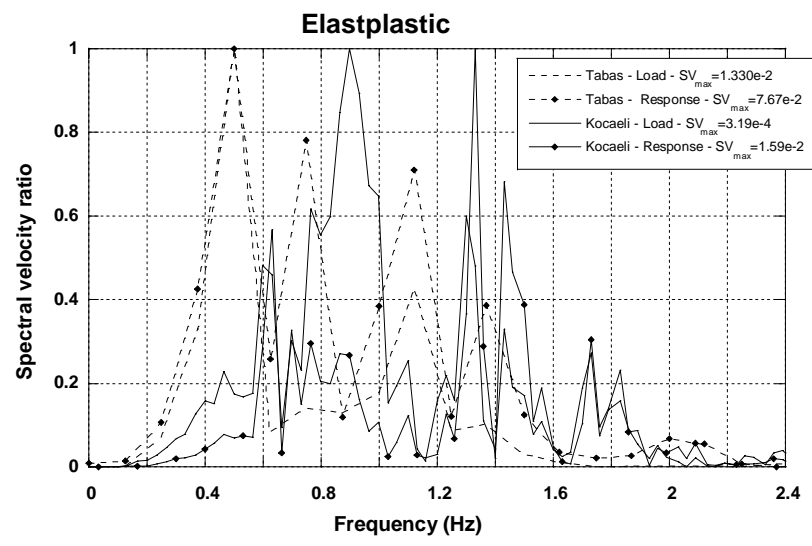

(b)

Fig. 14. Comparison of the spectra of the elastic (a) and elastoplastic (b) responses to the Kocaeli and Tabas earthquake records (The response is taken at the crest).

decrease of about $50 \%$ in the seismic amplification. This result could be attributed to the energy dissipation by plastic deformation and to the influence of plasticity on the reduction of the fundamental frequencies of the dam as illustrated Fig. 18, which shows the influence of plasticity on the spectral response at the crest of the dam. The Fourier spectrum illustrates a large component of amplification factor at natu-
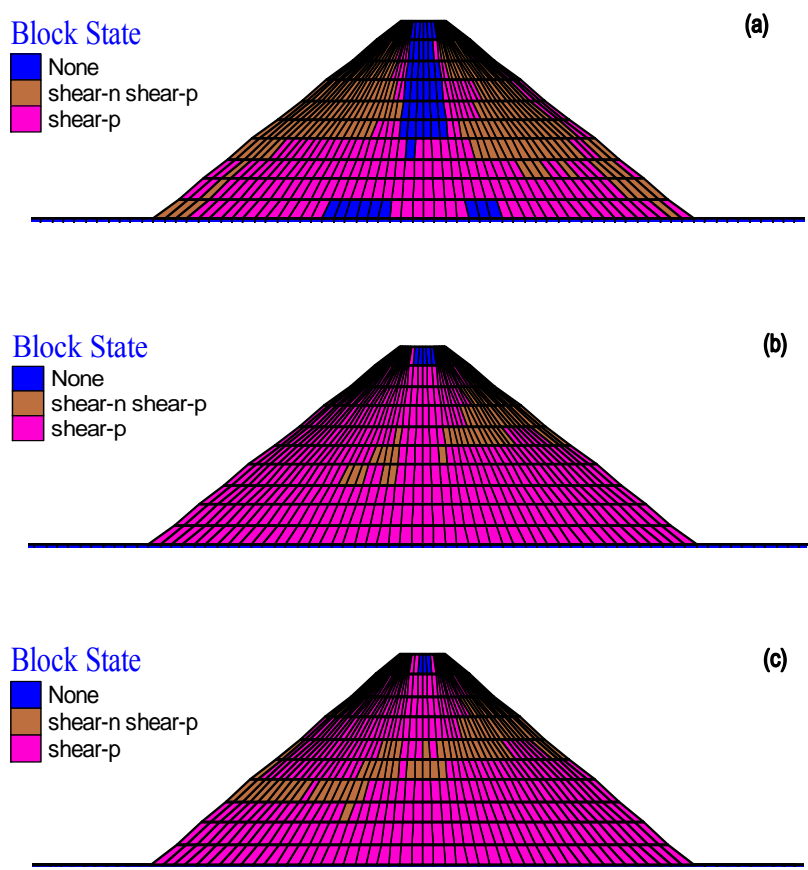

Fig. 15. Influence of the loading amplitude on the distribution of plasticity (Kocaeli earthquake record) : (a) $V_{a}=0.40 \mathrm{~m} / \mathrm{s}$, (b) $V_{a}=1.60 \mathrm{~m} / \mathrm{s}$, (c) $V_{a}=3.6 \mathrm{~m} / \mathrm{s}$.

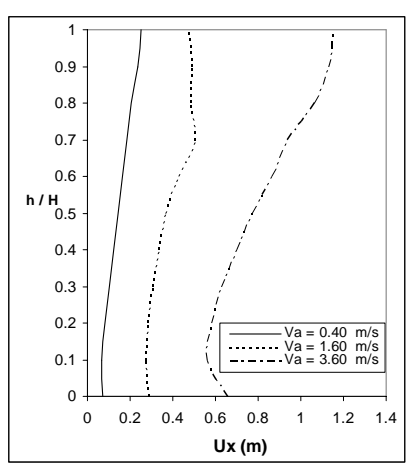

(Vertical axis of the dam)

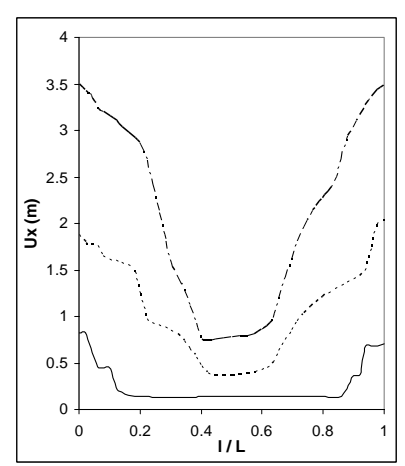

(Middle height of the dam)
Fig. 16. Influence of the loading amplitude on the maximum of displacement in the dam (Kocaeli earthquake record).

ral frequency of the dam and dominant frequency of loading record. The response spectra confirms also that the variation in core cohesion don't affect the overall response of the dam where we obtain practically the same result for model 1 and 3.

\section{Conclusions}

This paper included analysis of the seismic behaviour of earth dams. It corresponds to the response of the dam before water impoundment. Analyses were conducted for real 
Table 2. Core and shell cohesion for different models of the earth dam.

\begin{tabular}{lllll}
\hline & Model 1 & Model 2 & Model 3 & Model 4 \\
\hline Core cohesion $(\mathrm{kPa})$ & $100 \times 10^{3}$ & $100 \times 10^{3}$ & 100 & 100 \\
Shell cohesion $(\mathrm{kPa})$ & $100 \times 10^{3}$ & 0.1 & $100 \times 10^{3}$ & 0.1 \\
\hline
\end{tabular}

earthquake records. Non linear elastoplastic analyses show that the seismic loading induces plasticity in a large part of the shell and in the lower part of the core. The variation of the displacement in the middle height shows a sharp increase at the extremities, which could indicate the imminence of instability in this area. The upper third part of the crest should be designed carefully, and a design should take into account dominant frequency of the load and the dam where the movement could be significantly amplified. On the other hand, it can be observed that the plastic deformation leads to a decrease in the velocity amplification, in particular in the upper part of the dam. Parametric analysis shows that mechanical role of the core is not significant compared to the shell in the overall seismic induced response of the earth dam. Analysis shows that plasticity should be considered in the investigation of the seismic response of the dam, because it leads to a decrease in the natural frequencies of the dam together to an increase in energy dissipation, which could significantly affect the seismic response of the dam. Plastic analysis constitutes also a good tool for the verification of the stability of the dam under seismic loading.

Edited by: M. Contadakis

Reviewed by: A. Ouahsine and two other anonymous referees

\section{References}

Abouseeda, H. and Dakoulas, P.: Non-Linear Dynamic Earth DamFoundation Interaction Using a BE-FE Method, Earthquake Engineering and Structural Dynamics, 27, 917-936, 1998.

Cascone, E. and Rampello, S.: Decoupled Seismic Analysis of an Earth Dam, Soil Dynamics and Earthquake Engineering, 23, 349-365, 2003.

Chen, W. F. and Scawthorn, C.: Earthquake Engineering Handbook, CRC Press LLC, 2003.

Davis, C. A. and Sakado, M. M.: Response of the Van Norman Complex to the Northridge Earthquake, Association of Dam Safety Officials Conference Proceedings, Boston, MA, 241-255, 1994.

Gazetas, G.: Seismic Response of Earth Dams: Some Recent Developments, Soil Dynam. Earth. Eng., 6(1), 1-48, 1987.

FLAC3D, Itasca Consulting Group, FLAC: Fast Lagrangian Analysis of Continua, vol. I. User's Manual, vol. II. Verification Problems and Example Applications, Second Edition (FLAC3D Version 3.0), Minneapolis, Minnesota 55401 USA, 2005.

Kuhlmeyer, R. L. and Lysmer, J.: Finite Element Method Accuracy for Wave Propagation Problems, J. Soil Mech. Foundations Div., ASCE, 99(SM5), 421-427, 1973.

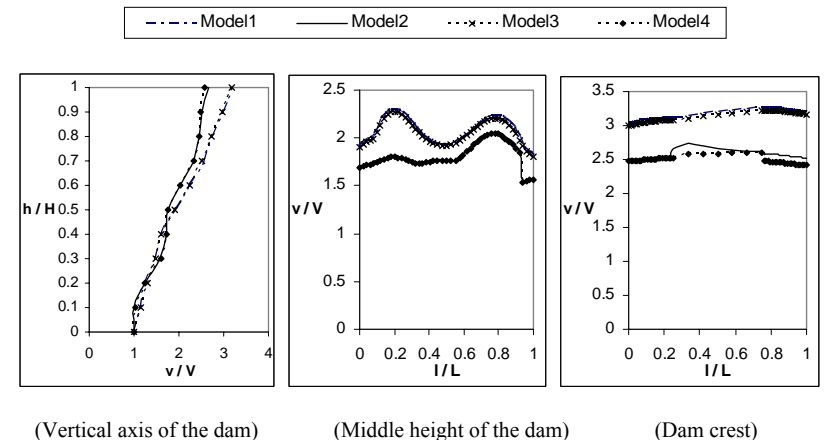

(Vertical axis of the dam)

(Middle height of the dam)

(Dam crest)

Fig. 17. Comparison of velocities results in different models for Turkey earthquake wave. (For model $1 \times$ model 4: see Table 2)

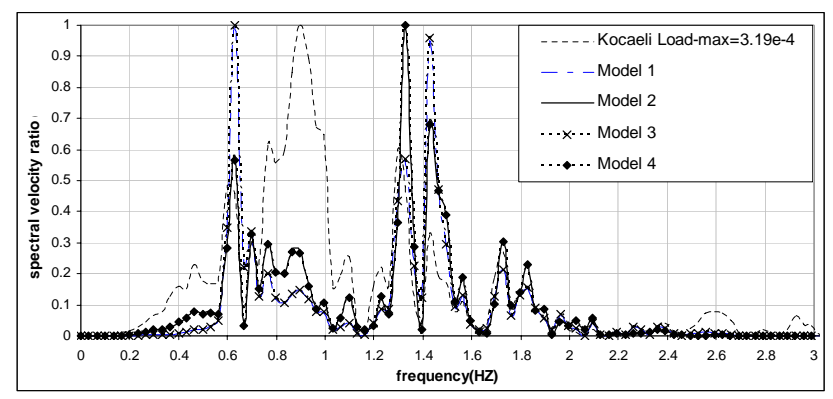

Fig. 18. Comparison of the spectra of the different models to the Kocaeli earthquake record.

Lin, J. and Chao, B.: Estimation of Shear Moduli and Damping Factors of Earth Dam Materials, Earthquake Engineering and Structural Dynamics, 19, 891-910, 1990.

Lokmer, I., Herak, M., Panza, G. F., and Vaccari, F.: Amplification of strong ground motion in the city of Zagreb, Croatia, estimated by computation of synthetic seismograms, Soil Dynam. Earth. Eng., (22), 105-113, 2002.

Ming, H. Y. and Li, X. S.: Fully coupled analysis of failure and remediation of lower San Fernando dam, J. Geotech. Geoenviron.Eng., ASCE, 129(4), 336-49, 2003.

Ohmachi, T. and Kuwano, J.: Dynamic safety of earth and rock fill dams, edited by: Balkema, A. A., Rotterdam, 160 p., ISBN 90-5410-265-9, 1994.

Özkan, M., YÖzyazicioglu, M., and Aksar, U. D.: An evaluation of Güldürcek dam response during 6 June 2000 Orta earthquake, Soil Dynamics and Earthquake Engineering, 26(5), 405-419, 2006.

Parish, Y., Shahrour, I., and Sadek, M.: Influence of the waterskeleton interaction on the seismic response of earth dams, Int. J. Multiphysics, 2(3), 267-277, 2008.

Paolucci, R.: Amplification of earthquake ground motion by steep topographic irregularities, Earthquake Engineering and Structural Dynamics, 31, 1831-1853, 2002.

Seed, H. B., Makdisi, F. I., and De Alba, P.: Performance of Earth Dams During Earthquakes, J. Geotechn. Eng., American Society of Civil Engineers, 104(GT7), 967-994, 1978.

Seed, H. B: Considerations in the Earthquake-Resistant Design of 
Earth and Rockfill Dams, 19th Rankine Lecture of the British Geotechnical Society, Geotechnique, 29(3), 215-263, 1979.

USCOLD (US Committee on Large Dams): Observed Performance of Dams during Earthquakes, Committee on Earthquakes, July, Denver, CO, 1992.

USCOLD (US Committee on Large Dams): Observed Performance of Dams during Earthquakes, 2, Committee on Earthquakes, October, Denver, CO, 2000.
Wood, J.: Earthquake-Induced Soil Pressures on Structures, Report EERL 73-05, California Institute of Technology, Pasadena, p. $311,1973$. 